\title{
Importância do diagnóstico presuntivo de abscessos encefálicos no sistema nervoso central
}

\author{
Importance of presumptive diagnosis of encefalic \\ abscess in central nervous system
}

\begin{abstract}
Adson Freitas de Lucena', Rachel Vasconcelos Tibúrcio', Herberth Duarte Cavalcante', Luís Edmundo Teixeira de Arruda Furtado ${ }^{2}$, Cícero Silvério de Paiva Neto ${ }^{3}$, Cláudio Henrique Moreira ${ }^{4}$, Gerardo Cristino Filho ${ }^{4}$
\end{abstract}

Lucena AF, Tibúrcio RV, Cavalcante HD, Furtado LETA, Paiva Neto CS, Moreira CH, Cristino Filho G. Importância do diagnóstico presuntivo
de abscessos encefálicos no sistema nervoso central//mportance of presumptive diagnosis of encefalic abscess in central nervous system. Rev Med (São Paulo). 2011 abr.-jun.;90(2):100-5.

RESUMO: Introdução: Abscessos cerebrais são caracterizados por uma coleção de exsudato no parênquima encefálico capazes de acometer indivíduos de qualquer idade, raça e sexo. Atenção especial deve ser dada a esses casos, pois sua apresentação clínica pode simular outros agravos, tornando importante ampliar o raciocínio para diversos diagnósticos diferenciais. O presente estudo visa o relato de caso de uma paciente admitida na Santa Casa de Misericórdia de Sobral com quadro sugestivo de cefaléia secundária. Material e Métodos: MEMA, 22 anos, universitária, evoluiu em 11 dias com cefaléia unilateral em região frontal esquerda e pulsátil. Essa cefaléia tinha caráter habitual, apresentava intensidade progressiva, associava-se a náuseas, melhorava com repouso e analgésicos, não havendo relato de fator desencadeante. Resultados: O exame neurológico evidenciou alteração no estado mental, com déficit de memória imediata e recente, compreensão e nomeação; além de desorientação temporo-espacial. Observou-se na Tomografia Computadorizada de Crânio (TCC) uma imagem hipodensa temporal esquerda, com halo hiperdenso de reforço após administracão de contraste. Conclusão: A mortalidade nos pacientes com abscesso cerebral pode variar entre $10-40 \%$, sendo bastante influenciada pelo estado clínico dos pacientes na admissão. Os sinais de alerta da cefaléia, também conhecidos como red flags, são de alto valor preditivo para agravos secundários cerebrais e devem ser considerados pelos profissionais de saúde que atuam em serviço de pronto atendimento. A TCC é uma importante ferramenta de diagnóstico e de avaliação dos abscessos cerebrais, sendo sua precocidade de realização fator prognóstico decisivo para o paciente.

DESCRITORES: Abscesso encefálico/diagnóstico; Cefaléia; Diagnóstico diferencial; Sistema nervoso central; Tomografia computadorizada por raio-x
ABSTRACT: Introduction: Brain abscesses are characterized by a exudate collection in the brain parenchyma able to reach individuals of any age, race and sex. Special attention should be given to these cases because their clinical presentation may mimic other diseases, making it important to extend the reasoning of possible differential diagnoses. This study is a case of a patient admitted to the Santa Casa de Misericórdia de Sobral with clues suggestive of secondary headache. Methods: MEMA, 22 years, university, developed in eleven days unilateral headache in the left frontal region and pulsatile. The headache was of normal character, intensity was progressive, associated to nausea, improves with rest and analgesics and no reports of triggering factor. Results: Neurological examination revealed changes in mental status, with lack of immediate and recent memory, understanding and naming, in addition to temporo-spatial disorientation. It was observed in CT scan of skull (CTS) a left temporal hypodense image with hyperdense halo of enhancement after administration of contrast. Conclusion: The mortality in patients with brain abscess can vary between $10-40 \%$ and is strongly influenced by the clinical status of patients on admission. The warning signs of a headache, also known as red flags, are of high predictive value for secondary brain injuries and should be considered by health professionals who work in service of the emergency room. The CTS is an important tool for diagnosis and assessment of brain abscesses, and its early implementation of decisive prognostic factor for patients.

KEYWORDS: Brain abscess/dagnosis; Headache; Diagnosis, differential; Central nervous system; Tomography, X-ray computed.

\footnotetext{
1. Acadêmico do Curso de Medicina - UFC Campus de Sobral, Sobral, CE, Brasil.

2. Neurologista do Serviço de Neurologia da Santa Casa de Misericórdia de Sobral, Sobral, CE, Brasil.

3. Otorrinolaringologista da Santa Casa de Misericórdia de Sobral, Sobral, CE, Brasil.

4. Neurocirurgiẫo do Serviço de Neurocirurgia da Santa Casa de Misericórdia de Sobral, Sobral, CE, Brasil.

Instituição onde o trabalho foi realizado: Santa Casa de Misericórdia de Sobral - Rua Antônio Crisóstomo de Melo, 919, $62010-550$ Sobral, CE, Brasil.

Endereço para correspondência: Rachel Vasconcelos Tibúrcio. Rua 7 de Setembro, 32, Bairro Campos dos Velhos - Sobral, CE, Brasil. CEP: 62030-160. e-mail: racheltiburcio@ hotmail.com
} 


\section{INTRODUÇÃO}

A bscesso cerebral é caracterizado por uma coleção purulenta no parênquima encefálico, resultado de uma infecção intracraniana ou extracraniana, bem como da invasão direta de microorganismos no cérebro decorrente de traumatismo crânio-encefálico ou de intervenções cirúrgicas ${ }^{1}$. Podem ocorrer em indivíduos de qualquer idade, raça e sexo em uma freqüência de 1500 a 2 mil novos casos por ano ${ }^{2}$. Dados estatísticos demonstram que até $8 \%$ de todas as lesões intracranianas que produzem efeito de massa são geradas por abscessos encefálicos, especificamente nos países em desenvolvimento, onde se encontra uma maior incidência de tratamentos inadequados de infecções ${ }^{3}$. Atenção especial deve ser dada a esses casos, pois sua apresentação clínica pode simular outras patologias, tornando importante ampliar o raciocínio clínico para o diagnóstico diferencial de cefaléias secundárias. A morbidade e a mortalidade decorrentes dessas lesões vem diminuindo a cada ano como conseqüência dos avanços diagnósticos, das intervenções cirúrgicas e dos novos regimes antibióticos. Entretanto, a descoberta de outros patógenos e de novos fatores predisponentes renovou a preocupação com o diagnóstico e com o tratamento dessa condição clínica.

Neste estudo, objetivou-se demonstrar a importância do diagnóstico presuntivo dos abscessos encefálicos, enfatizando o caso de uma paciente admitida na Santa Casa de Misericórdia de Sobral (SCMS) apresentando, após minuciosa anamnese e exame clínico, quadro sugestivo de cefaléia secundária.

\section{MATERIAL E MÉTODO}

MEMA, 22 anos, feminino, branca, universitária, procurou o pronto atendimento (PA) do hospital geral de seu município com queixa de cefaléia frontal unilateral à esquerda, de caráter habitual, pulsátil e com moderada intensidade, associada à náusea e à fonofobia, sem relato de fator desencadeante, com alívio após medicação analgésica endovenosa. Depois do atendimento, foi liberada para sua residência com o diagnóstico de enxaqueca. No dia seguinte, os sintomas recorreram, porém com incremento da intensidade da dor, tontura e confusão mental leve, retornando ao PA onde recebeu as mesmas medicações com alta posterior. Três dias após, retorna novamente ao hospital com a mesma sintomatologia acrescida de déficit de memória e de um episódio de perda da consciência.
Após a análise da tomografia computadorizada de crânio (TCC) solicitada, foi encaminhada para o hospital terciário de sua região com avaliação subseqüente do Serviço de Neurologia-Neurocirurgia da SCMS, sendo solicitado estudo de imagem por Ressonância Nuclear Magnética (RNM).

\section{RESULTADOS}

Ao exame físico, estava afebril, apresentando exame neurológico com alterações da memória recente, compreensão e linguagem, estando a nomeação prejudicada.

A TCC evidenciou uma imagem hipodensa ovalada de contornos precisos e membrana hiperdensa captante de contraste localizada em lobo temporal esquerdo (Figura 1). A RNM demonstrou uma área hiperintensa nas ponderações T2 e na difusão, além de hipointensidade nas ponderações T1, FLAIR e mapa ADC, com reforço anelar após uso intravenoso de contraste paramagnético. Observouse edema perilesional com efeito compressivo sobre o terceiro ventrículo e sobre os ventrículos laterais, associado ao desvio da linha média para direita em 0,7 centímetros (Figura 2).

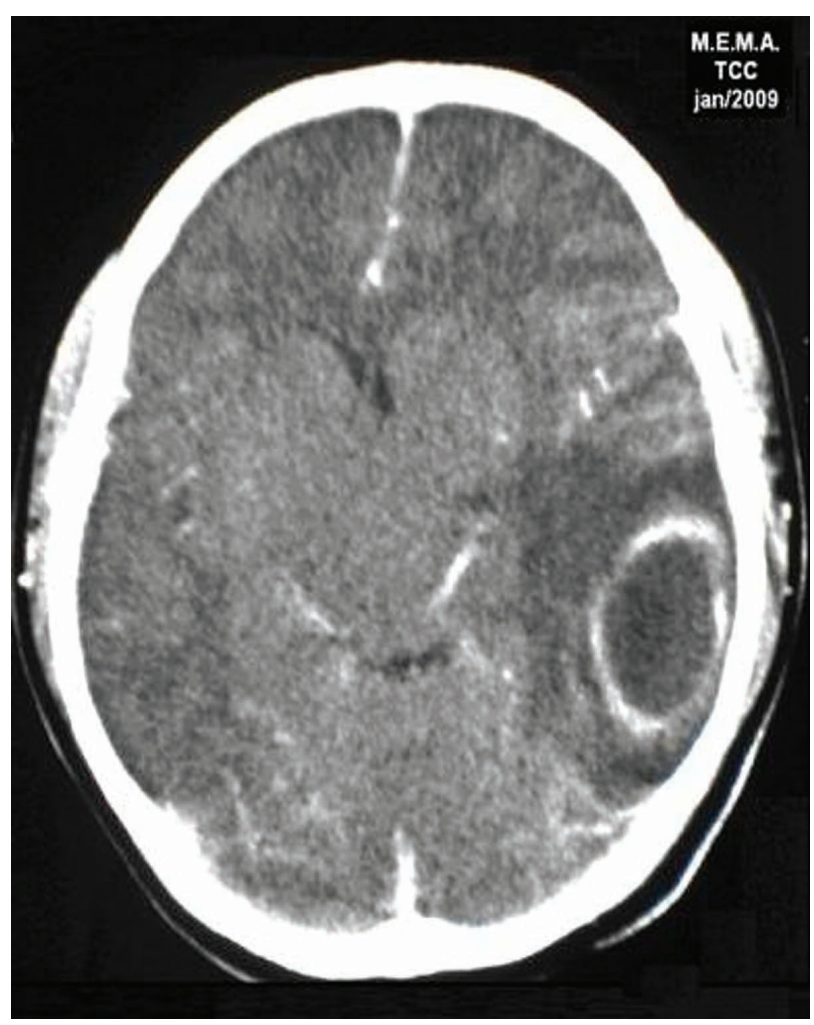

Figura 1. TCC evidenciando imagem hipodensa temporal esquerda, com halo hiperdenso central de reforço após administração de contraste 




Figura 2. RNM craniana da paciente, em ponderação T1 e em corte coronal, demonstrando massa cística no giro médio do lobo temporal esquerdo, com reforço anelar, após uso intravenoso de contraste paramagnético

Quatro dias após sua admissão, foi submetida à intervenção neurocirúrgica, na qual se evidenciou lesão cística encapsulada com conteúdo aparentemente purulento. O exame de cultura foi positivo, demonstrando bactéria Gram negativa Enterobacter sp. A paciente evoluiu com melhora clínica e tomográfica. Solicitou-se avaliação otorrinolaringológica com otoscopia normal. Foi realizado exame audiológico, tendo como resultado audiometria tonal e vocal dentro da faixa de normalidade bilateral.

Em sua evolução pós-operatória, teve melhora clínica considerável com remissão completa dos sinais e sintomas neurológicos apresentados em sua avaliação inicial.

\section{DISCUSSÃO}

Os abscessos cerebrais são infecções focais únicas ou múltiplas, caracterizadas por uma coleção de exsudato circundada por uma cápsula altamente vascularizada. Sua progressão pode ser descrita em quatro estágios: 1) cerebrite inicial, caracterizada por centro necrótico e inflamação local ao redor da adventícia dos vasos sanguíneos; 2) cerebrite tardia, quando ocorre alteração histológica mais significativa; 3) encapsulação precoce, entre o décimo e o décimo quarto dia, marcado pela resolução da cerebrite e aumento progressivo de macrófagos e fibroblastos; 4) encapsulação tardia, após o décimo quarto dia, quando há um centro necrótico bem definido e uma cápsula de colágeno espessa². Essas lesões são resultados da proliferação de bactérias piogênicas, fungos ou outros parasitas, quase sempre na substância branca cerebral ou cerebelar, configurando uma cavidade preenchida por pus ${ }^{1}$.

A importância dos abscessos encefálicos está em seu caráter expansivo, potencializado por intenso edema vasogênico em sua volta, podendo ser precursor de herniações cerebrais. Os abscessos também podem romper para o interior dos ventrículos, levando ao empiema ventricular e meningite, situação de grave morbidade para o paciente com taxa de mortalidade de até $75 \%$. Entretanto, os abscessos cerebrais não devem ser confundidos com empiemas (extradurais ou subdurais), que são coleções purulentas formadas em espaços preexistentes ao redor do parênquima cerebral².

Basicamente, existem cinco situações envolvidas no desenvolvimento do abscesso cerebral: 1) idiopática; 2) foco supurativo contíguo ao SNC; 3) disseminação hematogênica de foco infeccioso primário; 4) abertura da dura máter, cirúrgica ou traumática; 5) imunossupressão ${ }^{3}$. Contudo, a maioria dos abscessos cerebrais é causada por focos infecciosos contíguos, que se apresentam como uma única lesão superficial. Já os decorrentes da disseminação por via hematogênica, são normalmente múltiplos, profundos e de pior prognóstico, distribuindo-se em áreas de maior fluxo sanguíneo ${ }^{4}$.

Alguns fatores de risco já estabelecidos são doenças cardíacas congênitas, endocardite bacteriana, infecções pulmonares e bronquiectasia ${ }^{2}$. Esses distúrbios levam consigo um alto risco de infecção do coração e do pulmão, que podem então disseminar microorganismos patógenos para o cérebro ${ }^{3}$. Outros riscos incluem o uso ilícito de drogas (particularmente intravenosas), otite média e mastoidite, sinusites, infecção dentária, trauma craniano penetrante, infecção pós-cirúrgica e qualquer condição que reduza o funcionamento do sistema imune. Abscessos fúngicos são mais comuns em pacientes imunodeprimidos. O Toxoplasma gondii é o protozoário causador da infecção não-viral mais comum do sistema nervoso em pacientes com síndrome da imunodeficiência humana adquirida (SIDA).

Há cerca de 50 anos, estreptococos (viridans e beta-hemolítico), pneumococo e, principalmente, Staphylococcus aureus eram os microorganismos mais freqüentemente isolados ${ }^{2}$. Os resultados de estudos mais atuais têm mostrado que, em vez de aeróbios, os anaeróbios foram os que tiveram maior 
Lucena et al. Importância do diagnóstico presuntivo de abscessos encefálicos.

crescimento de sua presença nos abscessos ${ }^{1}$. Apesar disso, a flora microbiota é composta principalmente de aeróbios, como o Streptococcus spp, Enterobacteriaceae spp, Staphylococcus spp e Haemophilus $s p p^{(2)}$. Observa-se que a cultura de microorganismos aeróbios requer 2 a 3 dias para crescer; em comparação, os anaeróbios necessitam de apenas 24 horas. A baixa incidência de anaeróbios em estudos anteriores sugere uma inadequada manipulação do exsudato coletado. Novas técnicas de culturas também permitiram uma diminuição acentuada de culturas negativas, sendo, atualmente, o Bacteroides spp ( $B$. fragillis e $B$. melanogenicus), os estreptococos anaeróbios (peptoestreptococos), o Fusobacterium spp e o Propionumbacterium spp os mais encontrados ${ }^{2}$. Em neonatos, os abscessos surgem, principalmente, como complicação da meningite. A flora bacteriana encontrada na população neonatal é diferente, sendo o Proteus spp e o Citrobacter spp os agentes mais prevalentes ${ }^{2}$.

As manifestações clínicas podem se desenvolver subitamente ou gradualmente ao longo de duas semanas. A cefaléia é o sintoma mais freqüente, presente em 70 a $90 \%$ dos pacientes ${ }^{2}$. Atenção especial deve ser dada a esse fenômeno, pois desordens como trauma de cabeça e de pescoço, acometimento vascular do crânio ou cervical, alterações intracranianas não vasculares, neoplasias encefálicas, metástases cerebrais e infecções sistêmicas podem apresentar como sintomatologia inicial a cefaléia.

Identificar ou excluir as cefaléias secundárias baseando-se na anamnese e no exame neurológico é um ponto central na abordagem inicial do paciente com dor de cabeça. Sugere-se abordar a cefaléia buscando indícios cronológicos, pontos importantes na anamnese e acurado exame físico. Identificar marcos da história clínica é o primeiro passo, caracterizando quando a dor de cabeça teve início, o seu tempo de instalação e de evolução. É indispensável a busca por marcadores de doenças secundárias (Tabela 1), como início da dor acima dos cinqüenta anos, história patológica pregressa de rinossinusite, otite, meningite, imunodeficiência, neoplasias, doenças sistêmicas reumáticas, hemorragia subaracnóidea prévia, diagnóstico de migrânea, hidrocefalia tratada ou vigente, acidente vascular cerebral e trombose de seio venoso. No exame físico, devem-se buscar sinais e sintomas piréticos, indícios de irritação meníngea e papiledema. Cerca de $50 \%$ dos pacientes que apresentam abscesso encefálico manifesta sinais e sintomas piréticos mínimos, sendo a febre alta uma manifestação incomum. A tríade clássica de febre, cefaléia e sinais focais ocorre em menos de $50 \%$ dos pacientes na maioria dos estudos.
Tabela 1. Sinais de alarme para cefaléia (red flags)

\begin{tabular}{l} 
Início após 50 anos \\
Início súbito \\
Características progressivas (intensidade, freqüência, \\
duração) \\
Caráter intenso e persistente \\
Cefaléia matinal ou que acorda o paciente à noite \\
Cefaléia recente em paciente com diagnóstico de neoplasia \\
ou SIDA \\
Doença sistêmica com sinais piréticos (febre, rigidez de \\
nuca, rash cutâneo) \\
Sinais neurológicos focais \\
Edema de papila \\
Resistente ao tratamento convencional \\
\hline
\end{tabular}

Concatenando as pistas colhidas com propedêutica bem executada, podemos aventar o diagnóstico diferencial de cefaléia secundária, situação que impõe investigação com exames complementares em caráter de urgência. No caso descrito, a paciente apresentou alteração do estado mental e de funções corticais específicas na evolução final do quadro. Deve-se ressaltar que a suspeição para o diagnóstico final foi norteada pelo paroxismo neurológico presente na história clínica. Portanto, o diagnóstico presuntivo de acometimento infeccioso do SNC foi a soma da epidemiologia desse agravo, da presença de sinais de alarme para cefaléia secundária e da avaliação de exames complementares de neuroimagem, visto que a paciente não se encontrava em nível adequado de consciência para fornecer uma anamnese fidedigna. Outra ponderação a ser considerada é o desvelo a ser empreendido quando um paciente busca 0 pronto atendimento com queixa principal de cefaléia. Observa-se neste relato uma baixa aplicabilidade dos critérios de cefaléia secundária no serviço de emergência, resultando em internação hospitalar com incremento de morbidade.

Quando o médico suspeita de um abscesso cerebral, exames baseados em neuroimagem devem ser requisitados, a exemplo da TCC e da RNM. No entanto, esses exames têm limitações, pois as características da imagem de focos supurativos são inespecíficas e podem simular massas císticas de diferentes etiologias ${ }^{2}$. Exames adicionais, como a punção do abscesso por estereotaxia, podem ser necessários para que se possam descartar outras possibilidades diagnósticas. O exame do líquor, quando é possível realizar, mostra menos alterações do que nas meningites, já que a lesão está dentro do parênquima e sem comunicação com o espaço subaracnóideo. Há pleocitose e hiperproteinorraquia 
discretas, sendo a glicorraquia normal ${ }^{1}$.

O tratamento do abscesso cerebral envolve a combinação de drenagem neurocirúrgica por craniotomia ou estereotaxia e utilização de medicamentos. A definição de um sítio primário como fonte do abscesso cerebral tem grande importância na escolha dos antibióticos a serem ministrados, principalmente quando não se consegue isolar um agente específico. Em cerca de 10\% dos casos, no entanto, a fonte original da infecção não pode ser identificada, optando-se pelo tratamento antibioterápico empírico ${ }^{4}$.

O tratamento exclusivamente medicamentoso fica restrito aos abscessos localizados em áreas eloqüentes ou de difícil acesso, abscessos múltiplos, lesões menores que três centímetros, estágios iniciais da cerebrite, paciente com alta morbidade e meningite ou ependimite ${ }^{2}$. O tratamento dos abscessos encefálicos deve ser instituído nas primeiras seis horas da admissão. Quando possível, deve-se fazer coleta do conteúdo purulento, bem como três amostras de hemocultura para se analisar qual o provável microorganismo responsável pela formação da lesão ${ }^{5}$. O esquema empírico padrão baseia-se na cobertura de gram positivos e negativos, assim como de agentes aeróbios e anaeróbios ${ }^{4}$. Em geral, a antibioticoterapia dura de seis a oito semanas, com perspectiva de controle imaginológico semanais ou caso haja piora clínica ${ }^{2}$. Como o tratamento é prolongado, o esquema empírico deve ser reajustado mediante resultado dos exames para comprovação microbiológica ${ }^{4}$. Entretanto, deve-se ficar atento, pois, após o término das medicações, o abscesso pode permanecer de três a onze meses, sendo necessário repetir a TCC a cada duas a quatro semanas até seu completo desaparecimento. Em pacientes que desenvolvem hipertensão intracraniana e edema cerebral, condições que podem lesar o cérebro de forma permanente, administram-se fármacos que reduzem o edema cerebral e a pressão intracraniana. Ressalta-se que os corticosteróides devem ser utilizados apenas por um curto período de tempo, já que essas medicações reduzem a penetração dos antibióticos no abscesso(2). Caso não haja efeito de massa, o esquema antibioticoterápico é instituído isoladamente ${ }^{5}$.

O tratamento inicialmente cirúrgico é feito quando há diagnóstico diferencial com tumores primários, metástases cerebrais ou outras infecções não-bacterianas; proximidade com ventrículos laterais; efeito de massa significativo; abscessos fúngicos, multisseptados e traumáticos associados a corpo estranho².

Com a facilidade das técnicas de neuroimagem, principalmente a TCC, a mortalidade passou a ser inferior a $15 \%$, apesar de ter mantido altos níveis de morbidade, com seqüelas, incluindo afasia e convulsões, em torno de $20 \%$ e epilepsia tardia em $25 \%$ dos pacientes com diagnóstico de abscesso encefálico ${ }^{2}$. Os piores prognósticos reservam-se aos casos em que há alteração do nível de consciência no início do tratamento ou quando há ruptura do abscesso encefálico ${ }^{2}$.

\section{CONCLUSÃO}

Infecções purulentas do parênquima cerebral ainda são agravos de saúde com elevada taxa de mortalidade, variando entre 10 a $40 \%$ quando diagnosticadas tardiamente. O desfecho clínico do paciente é influenciado essencialmente pela sua apresentação inicial na admissão hospitalar'. Os focos infecciosos são hoje bem estabelecidos, contudo, até $10 \%$ dos abscessos encefálicos não possuem foco de propagação definido. Os germes colonizadores dependem do foco primário infeccioso e de fatores predisponentes, ressaltando a busca de imunossupressão para suspeição de abscessos fúngicos e de parasitas sistêmicos. A cultura do abscesso cerebral atesta dois ou mais agentes em 20 a $60 \%$ dos casos, sendo ela negativa em $30 \%$. Flora mista pode ser detectada em até $1 / 3$ dos casos ${ }^{5}$.

Os sinais de alerta da cefaléia, também conhecidos como red flags, são de alto valor preditivo para agravos secundários cerebrais e devem ser considerados pelos profissionais de saúde que atuam em serviço de PA. Quando existem sinais e sintomas de lesão expansiva progressiva, estes são observados em quatorze dias de evolução da coleção purulenta, sendo o déficit neurológico focal o sinal mais presente no exame clínico desses pacientes ${ }^{2}$. $O$ médico deve apresentar forte suspeição clínica para aventar o diagnóstico de infecção do SNC, pois os sinais infecciosos são geralmente escassos.

A TCC é um importante elemento para o diagnóstico e para a avaliação da forma de tratamento dos abscessos cerebrais, sendo a sua precocidade de realização fator prognóstico decisivo para o paciente. A análise do líquido cefalorraquidiano deve ser postergada até a TCC descartar efeito de massa sobre o parênquima cerebral. Quando aventado o diagnóstico de abscesso cerebral por exames de neuroimagem, deve-se excluir neoplasia com necrose central, encefalite viral focal, doenças parasitárias, hematomas e infartos cerebrais.

A morbidade do abscesso encefálico depende da localização da infecção e do grau de degradação tissular $^{5}$. É importante salientar que o melhor prognóstico e a redução da taxa de mortalidade dependem da precocidade do tratamento instituído. 


\section{REFERÊNCIAS}

1. Pereira CU, Góis CRT, Camelo RM. Complicações intracranianas decorrentes de infecções otorrinolaringológicas. Arq Bras Neurocir. 2005;24(3):98111.

2. Dauar RFB. Abscessos cerebrais. In: Braga FM, Melo PMP, Schor N. Neurocirurgia - guias. São Paulo: Manole; 2005. p.607-15.

3. Pereira CU, Silva AD, Carneiro-Leão JDB, Sotero ALM, Araújo CSCA, Porto CPS. Abscesso cerebral associado à cardiopatia congênita cianótica, Considerações sobre 17 casos. Arq Bras Neurocir. 2001;20(1-2):41-50.

4. Vialogo JGG, Sanches MCA. Abscesso cerebelar tratado clinicamente. Arq Neuropsiquiatr. 2001;59(3B):824-8.

5. Colli BO. Coleções e abscessos cerebrais. In: MeloSouza SE. Tratamento das doenças neurológicas. Rio de Janeiro: Guanabara Koogan; 2008. p. 29-31.

6. Oliveira DVG, Pereira CAP, Barata $\mathrm{CH}$, Colombo AL. Abscesso cerebral por Nocardia $s p$ em paciente imunossuprimido. Rev Soc Bras Med Trop. 2000;33(6):609-12.

Recebido em: 10/01/2011

Aceito em: 11/04/2011 